\title{
Comparing Interpersonal Defense Theory and Interpersonal Reconstructive Therapy and Their Views of Sharon's Case
}

\author{
MICHAEL A. WESTERMAN ${ }^{a, b}$
}

${ }^{a}$ New York University

${ }^{\mathrm{b}}$ Correspondence regarding this article should be sent to: Michael A. Westerman, Department of Psychology, New York University, 6 Washington Place, Fourth Floor, New York, NY 10003, USA.

Email: michael.westerman@,nyu.edu

\begin{abstract}
This paper compares the approaches to Sharon's case presented in two articles that appear earlier in this module, my paper (Westerman, 2021a), which was based on Interpersonal Defense Theory, and the paper by Critchfield, Dobner-Pereira, and Stucker (2021a), which was based on Interpersonal Reconstructive Therapy (IRT). I begin by considering differences in general between the ways in which these two perspectives approach case formulation. I then turn to comparing the formulations of Sharon's case based on the two perspectives. Among other things, this part of the paper contrasts IRT's focus on copy processes and the Gift of Love with Interpersonal Defense Theory's focus on functionalist processes that involve the temporal organization of the parts of noncoordinating defensive interpersonal patterns. The second half of the paper compares the treatment implications of the two approaches in general terms and as they relate to Sharon's case in particular. Implications for treatment are discussed regarding both insight-oriented interventions and enacted interventions at the level of therapy relationship processes.
\end{abstract}

Keywords. Interpersonal Defense Theory; Interpersonal Reconstructive Therapy (IRT); case formulation; insight-oriented interventions; enacted interventions; case study; clinical case study

Comparing the approaches to Sharon's case presented in earlier articles in this set of contributions, my paper (Westerman, 2021) based on Interpersonal Defense Theory (e.g., Westerman, 2018, 2019) and the paper by Critchfield, Dobner-Pereira, and Stucker (2021a) based on Interpersonal Reconstructive Therapy (IRT; e.g., Benjamin \& Critchfield, 2010), leads to an intriguing observation. On the one hand, the two approaches are similar in several respects. Both are interpersonal approaches. They also share in common the views that patients' symptoms are closely linked to dysfunctional patterns of interpersonal behavior and that change in those patterns is key to good outcomes. Moreover, both incorporate ideas from the Structural Analysis of Social Behavior (SASB; e.g., Benjamin, 1979).

Nevertheless, on the other hand, notwithstanding these noteworthy similarities, there are very important differences between these two perspectives. In the first half of this paper, I consider differences in their approaches to case formulation, beginning with how they conceptualize cases in general and then turning to their formulations of Sharon's case. In the 
second half of the paper, I discuss how the two perspectives differ in their implications for treatment, again, turning first to differences in treatment implications for therapy cases in general and then for Sharon's case in particular.

\section{COMPARING CASE FORMULATIONS}

\section{Comparing the Two Approaches to Case Formulation in General}

Interpersonal Defense Theory and IRT differ in three fundamental respects. Those fundamental differences lead to different viewpoints on patients' problematic interpersonal patterns regarding the nature of those patterns, how they develop, and why they persist, which are reflected in their approaches to case formulation.

As I discussed in my earlier paper in this module, Interpersonal Defense Theory provides process models of interpersonal phenomena. Two of the three fundamental points refer to what those process models are like. One point is that these process models are based on the idea that each contribution a person makes to an exchange is a part of doing something with someone else that either fits together or fails to fit together with what else transpires as the interaction develops over time to forge that larger action (Westerman, 2005). According to this idea, individual interpersonal behaviors are not isolable events.

As I see it, IRT does not incorporate this first fundamental point about interpersonal behavior. For example, Critchfield et al. (2021) identified "patterns" defined by groups of behaviors that occurred in unspecified temporal relationship to one another. That is quite different from treating interpersonal behaviors as fundamentally diachronic in nature because a crucial feature of those behaviors concerns how they mesh with each other as an interaction proceeds over time.

The idea that interpersonal behaviors are parts of doing something also links to a second fundamental commitment. Interpersonal behavior patterns are not simply temporally organized structures or forms. Whenever a person engages in an interpersonal interaction, he or she will be pursuing a goal or a complex set of goals. Interpersonal Defense Theory incorporates this idea by offering process models that are functionalist accounts. How an individual behaves as part of pursuing a goal or goals in an interaction will affect how the other person responds, which, in turn, will affect how the first person subsequently behaves. ${ }^{1}$

IRT takes a very different approach. It does not offer functionalist models. Instead, it provides descriptive accounts that focus on what interpersonal behavior is like rather than on how a person is trying to influence another person's responses by acting in a particular way, or what responses the first person actually ends up promoting by acting that way.

The third fundamental point is that Interpersonal Defense Theory treats interpersonal action patterns as primary. The theory includes intrapsychic processes and recognizes that they play very important roles, but it treats them as subprocesses nested within patterns of interpersonal action, for example, intrapsychic defense mechanisms that support interpersonal defenses (Westerman \& Steen, 2007). In IRT, intrapsychic processes, specifically, processes 
regarding internalized attachment figures, play a more central role, as Critchfield et al. (2021) made clear.

\section{Comparing Views of the Nature of Problematic Interpersonal Processes}

The fundamental point about the importance of functionalist considerations plays a key role from the word go in how Interpersonal Defense Theory conceptualizes the nature of problematic interpersonal processes. According to one of the theory's tenets, interpersonal defenses are attempts to negotiate conflicts between pursuing a central interpersonal wish (which is one component of case formulations based on the theory) and avoiding a highly salient negative response by others that could result from pursuing the wish (which is another component of formulations). In addition to this tenet, there are tenets about causal processes, including the tenets about feed-forward effects (which include two other components of formulations, positive responses distinct from the wish and negative responses distinct from the fear), which are about how interpersonal defenses actually affect another person's responses, and the tenet about how those responses by significant others, in turn, maintain the first person's defensive pattern.

IRT case conceptualizations, on the other hand, offer descriptive accounts of problematic interpersonal patterns. They do not consider an individual's goal or goals when he or she relates to others, with the exception of a very different kind of goal, the Gift of Love, which I will discuss shortly. Therefore, unlike Interpersonal Defense Theory, they do not consider the idea that problematic interpersonal patterns might be attempts to realize two conflicting goals.

The fundamental point I discussed earlier about focusing on whether and how interpersonal behaviors mesh with each other as an exchange proceeds over time is incorporated in several features of Interpersonal Defense Theory. Most notably, this idea appears in the view that problematic interpersonal behavior patterns are characterized by recurring failures of coordination (another component of formulations based on the theory). The focus on coordination also directly links to the previous point about the theory's functionalist approach because (as I explained in my earlier paper in the module), (a) according to the theory, noncoordinating patterns are the ways in which people try to negotiate wish-fear conflicts, and (b) the nature of those patterns explains why they actually lead to avoiding the feared-response, work against the wished-for response, and promote negative responses distinct from the fear and positive responses distinct from the wish.

By contrast, as I noted earlier, IRT case formulations do not include the idea that individual interpersonal behaviors are parts of larger action patterns that should mesh over time as an interaction proceeds. Instead, researchers or therapists guided by IRT attempt to identify a group of behaviors that characterize a patient's pattern. As a result, the IRT approach does not lead to identifying patterns of recurring coordination failures, or help us understand why people engage in those patterns of behavior or how those patterns affect what actually occurs in relationships.

One observation about procedures is relevant here. As Critchfield et al. (2021, p. 46) explained, the first step in the IRT approach to case formulation is identifying current 
interpersonal patterns based on patients' relationship narratives. Very often, it is not possible to learn about the temporal organization of interpersonal exchanges from such narratives, especially with regard to questions about meshing/coordination. On the other hand, working from narratives fits with identifying whether a person interpersonal pattern includes a particular constellation of individual behaviors. When Interpersonal Defense Theory is used to study psychotherapy, it calls for examining videotaped therapy interactions as the first step in arriving at a case formulation, in large measure because that provides a way to consider how/whether individual behaviors mesh together over time. Interpersonal Defense Theory calls for considering patients' relationship narratives as well, but it also calls for carefully evaluating whether any given narrative provides useful information about coordination processes.

\section{Comparing Views about the Development of Problematic Interpersonal Patterns}

Both IRT and Interpersonal Defense Theory hold the view that childhood experiences typically play a crucial etiological role. However, they differ in their accounts of that role.

According to IRT, a child develops problematic behavior patterns as a result of three copy processes, recapitulation, identification, and introjection. IRT case formulations attempt to identify ways in which any or all of these copy processes are reflected in a patient's current life. This is done by comparing, on the one hand, descriptions of a patient's interpersonal behavior in current relationships with significant others and intrapsychic processes concerning how the patient treats him- or herself currently with, on the other hand, information about early relationships with attachment figures. In IRT, problematic patterns are referred to as "Red." Clinicians and researchers typically find that current Red patterns are copies of early patterns.

Interpersonal Defense Theory includes an account of the development of problematic interpersonal processes that differs from the one offered by IRT in several respects. One difference is that case formulations based on Interpersonal Defense Theory do not make use of notions about copy processes. The copy processes are some of the theoretical principles associated with SASB. As I explained in my earlier paper in this module, Interpersonal Defense Theory only makes use of another one of those principles, complementarity. Another difference is that the developmental account included in Interpersonal Defense Theory identifies three key phases, as I explain below, not only the two of interest in IRT (childhood and later in life). Most importantly, Interpersonal Defense Theory offers a developmental account that is based on functional concerns.

According to Interpersonal Defense Theory, wish-fear conflicts have their roots in repeated experiences in which a child wants to engage significant others in some kind of interaction (which later becomes the central wished-for relationship) and behaves in a way that would be the child's part of the desired relationship, but others respond in a particular negative way (which becomes the central interpersonal feared response) rather than responding in the desired manner (which becomes the wished-for response). For present purposes, I will refer to this period of time as the first phase. During the second phase, while still a child or as a preadolescent, the person develops a defensive noncoordinating interpersonal pattern as an attempt to pursue the wish while simultaneously trying to avoid the fear. The upshot is that significant others do not respond to the child in the feared or wished-for manner, but instead respond to him 
or her with particular negative responses distinct from the fear and positive responses distinct from the wish.

This overall pattern of the individual's behavior and how others relate to the person may well continue into later life (the third phase). When that is the case, the individual's interpersonal behavior will be similar to his or her interpersonal behavior in the second phase. However, this similarity is not due to the workings of copy processes; it is the result of functional processes related to the individual's interpersonal wishes and fears (more on this shortly). Note that these ideas about development are directly linked to all five components of case formulations based on Interpersonal Defense Theory, the wish, fear, defensive noncoordinating patterns, and the negative response distinct from the fear and positive response distinct from the wish that the defensive pattern promotes.

\section{Comparing Explanations of Persistence}

Why do people persist in engaging in dysfunctional patterns of interpersonal behavior? Finding a good answer to this question is very important. To return to something Wachtel (2017, p. 519-520, italics in original) said that I quoted in my earlier article in this set of papers, "in order to help the person generate change in his or her life, we need to understand with great clarity how he or she keeps it the same." IRT and Interpersonal Defense Theory case formulations offer different answers to this question.

IRT addresses the issue in part with its idea about copy processes. But even if we were to accept that copy processes might account for why a patient repeats a "Red" pattern from childhood on some occasions as an adult, this idea does not explain why the patient would go on to copy the Red pattern again and again, given that behaving that way leads to recurring problems. IRT can respond to this objection, however, because its case formulations also include another part, the hypothesis of the Gift of Love (GOL) hypothesis.

According to that hypothesis, people continue to engage in dysfunctional interpersonal behavior patterns to "remain faithful to the rules and values learned with...important others in a continued attempt to get it right by them" (Critchfield et al., 2021, p. 46), that is, to "finally receive love and understanding from the internalized family in the head" (Critchfield et al., 2021, p. 55). This last quote makes it clear that intrapsychic processes related to internalized attachment figures play a central role in IRT, as I pointed out earlier when I discussed the third fundamental way in which IRT and Interpersonal Defense Theory differ.

The GOL hypothesis is a kind of functionalist concept. A person continues to relate to others in problematic ways because he or she is pursuing a goal. Nevertheless, this functionalist notion is very different from the ones included in Interpersonal Defense Theory because the goal in the GOL involves inner processes, "remain[ing] faithful to [old] rules and values" in the hope that all will become "right" with the "internalized family in the head," a family that might even be made up of significant others who are no longer alive.

Interpersonal Defense Theory places primary emphasis on action, not inner processes, and this is evident in its functionalist account of persistence. According to that account, people 
are not motivated to continue to behave in dysfunctional ways by supposedly stable inner representations "within" the person. Rather, problematic patterns persist because people are trying to change what their actual relationships are like, specifically, trying to make them be different from what they were like in the first and second phases and to date in the third phase. However, they go about trying to change things in ways that keep them the same. ${ }^{2}$

As I explained in my earlier paper in this module, according to the theory, people engage in defensive behavior because they are trying to realize their central interpersonal wishes and also avoid their central fears. Nevertheless, interpersonal defenses actually lead to certain responses by significant others - the feed-forward effects - that make it likely that the first person will continue to behave defensively, even though those responses are different from what the first person was aiming for (because they make wished-for responses unlikely) and the same as how others have responded to the first person in the second phase and in the third phase to date (negative responses distinct from the fear and positive responses distinct from the wish).

\section{Comparing Formulations for Sharon's Case}

I now turn to comparing the formulations for Sharon's case based on IRT and Interpersonal Defense Theory. I begin by considering the analyses the two perspectives offer of Sharon's current relationships and then continue to follow the order of steps IRT recommends for arriving at a formulation in later sections.

\section{$\underline{\text { Comparing Conceptualizations of Sharon's Current Behavior }}$}

My remarks so far make it clear that the two theoretical perspectives take very different approaches to examining a patient's current relationships. I have already discussed the main points that are relevant here, which are that IRT takes a more purely descriptive approach whereas Interpersonal Defense Theory takes as its goal arriving at an explanatory account that is functionalist in nature and involves considering the functional roles played by parts of interpersonal patterns of behavior by virtue of the temporal organization of those patterns. I also previously mentioned that the two approaches differ with respect to methods in that IRT places more emphasis on patients' narratives whereas Interpersonal Defense Theory relies more heavily on observations of ongoing exchanges.

There are other differences as well. IRT formulations include different descriptions for patients' different relationships. As a result, IRT formulations have a great deal of descriptive richness and they are very complicated. Formulations based on Interpersonal Defense Theory are complex, but in comparison to IRT, they offer simpler conceptualizations. Interpersonal Defense Theory calls for identifying a single recurring defensive pattern in a patient's behavior with others. Arriving at a formulation of that pattern requires a greater degree of inference than is required by IRT because the pattern has to be recognized notwithstanding the different concrete ways in which it appears from one relationship to another and from one point in time to another in any one relationship.

The upshot of these differences is that it is not easy to compare formulations of a patients' current relationships based on the two approaches. Nevertheless, it is possible to 
discover some points of agreement and some points of disagreement. Many of the latter are due to ways the two formulations offer different answers because they are asking different questions.

Critchfield et al. (2021, pp. 51-52 \& 60) provided different descriptions of Sharon's relationships with different important people in her life. However, they also offered a general characterization of her current relationships (pp. $50 \& 60$ ). That characterization describes two patterns. I will consider the first pattern. ${ }^{3}$

According to Critchfield et al.'s (p. 60) description, Sharon "feels misunderstood, angry. Complies resentfully, defies indirectly, and withdraws herself. Withdrawal is seen as [the] primary way of punishing or coercing others in response to conflict." Also, "loved ones are perceived as controlling, judgmental, intrusive, not understanding her needs even when combined with love or concern for her."

Recall that according to my formulation, much of Sharon's interpersonal behavior was characterized by a noncoordinating defensive pattern in which she persistently, stubbornly pressed on with her point of view and tried to get interactions to proceed along the lines she wanted to pursue, while she also repeatedly appeared to agree with and defer to the other person. Sharon pressed on with her viewpoint as a way of pursuing her wish by acting independently and taking stands. In SASB terms and as depicted in Figure 1, this refers to 218 (own identity and standards), 217 (assert on own), and 216 (put cards on table). Her repeated bids in which she agreed with and deferred to the other person served to avoid her fear by again and again derailing her efforts to pursue her wish.

With regard to how others acted towards Sharon, her defensive pattern worked against significant others responding to her in her wished-for manner by affirming her and showing appreciation for her independence and viewpoints (118, encourage separate identity; 117, you can do it fine; 116, carefully fairly consider). It also worked against others responding to her in the manner she feared by showing that they were uninterested in her and staying uninvolved with her (126, ignore her, pretend she is not there; 125 , neglect her interests and needs). Instead, it pulled for benevolently managing responses $(144,145,146,147,148)$ that were positive but distinct from her central wish, and hostile controlling and angry, attacking responses $(135,136$, 137,138 , and 130,131) that were negative responses distinct from Sharon's central fear.

Some Points of Similarity. The sense in which there is some agreement in the IRT and Interpersonal Defense Theory formulations of Sharon's behavior is rather complicated, but noteworthy. The IRT formulation does not say that Sharon's interpersonal pattern included parts in which she appeared to agree with and defer to the other person, but it does include "complies resentfully." Perhaps curiously, this reflects appreciation on the part of Critchfield et al. (2021) of what I called the "overall package" of Sharon's behavior in my earlier paper in this module.

In this respect, the IRT formulation considers context, although it does not take account of context in a way that involves tracing out the temporal organization of individual behaviors.

Using narratives makes it somewhat likely that the force of the overall pattern becomes evident, but less likely that individual parts of the pattern will be identified as such. The Interpersonal 
Defense Theory approach, by contrast, identifies the significance the parts have in themselves and also considers how the ultimate significance of those parts rests on the role they play in the overall pattern as interactions proceed over time.

Hence, my account recognizes that, taking her behaviors individually, Sharon often agreed/deferred to the other person, but it also definitely appreciates that as parts of her pattern, those behaviors contributed to making it likely that others would respond to Sharon in ways that are very different from how they would respond to someone who simply agreed/deferred. In fact, in the context of the overall pattern, the ultimate significance of Sharon's agreeing/deferring behaviors should be characterized very much along the lines of "complies resentfully" because Sharon repeatedly shifted from agreeing to go back to the line of discussion she wanted to pursue. As a result, those behaviors contributed to the feed-forward effects identified in the account based on Interpersonal Defense Theory.

A similar point can be made about "defies indirectly" in the IRT formulation. The formulation based on Interpersonal Defense Theory includes "acting independently and taking stands," but in the context of the overall package of Sharon's interpersonal pattern, her bids to take a stand repeatedly derailed bids in which she appeared to agree with and defer to others. As a result, the significance of her efforts to take a stand ultimately was very much like "defying indirectly," as in the IRT formulation. Here again, as part of the overall pattern, those efforts contributed to making it likely that Sharon's interpersonal pattern would lead to the feed-forward effects identified in the formulation based on Interpersonal Defense Theory.

The IRT formulation of how others behaved toward Sharon is quite similar to the one based on Interpersonal Defense Theory. According to both, others did not affirm Sharon or show appreciation for her independence (i.e., the responses she wished-for as per the Interpersonal Defense Theory conceptualization). In addition, according to both, others did not ignore/neglect her (i.e., her feared response as per the Interpersonal Defense Theory conceptualization). ${ }^{4}$

What about how others did behave towards Sharon? According to the IRT formulation, others were "judgmental" and "intrusive." These descriptors agree with the view based on Interpersonal Defense Theory that the feed-forward effects of Sharon's defensive pattern included hostile controlling responses by others. The IRT observation that others "[did] not understand [Sharon's] needs even when combined with love or concern for her" is similar, although not identical, to one of the other feed-forward effects according to Interpersonal Defense Theory, benign management. Finally, the IRT view that others behaved in a "controlling" manner with Sharon agrees with the Interpersonal Defense Theory-based formulation in that most of the feed-forward effects of Sharon's pattern involved high levels of control.

Differences in the Two Formulations. The main differences between the two formulations of Sharon's current relationships follow from the fact that IRT and Interpersonal Defense Theory address different issues. IRT focuses on identifying features of interpersonal behavior that characterize a patient's relationships. Interpersonal Defense Theory attempts to provide accounts of what a patient is trying to do and how he or she attempts to pursue those interpersonal goals, and what are the actual effects of the patient's interpersonal pattern and why it has those effects. 
It considers those questions about functional processes in a way that involves examining the temporal organization of the parts of the patient's pattern.

One upshot of these differences is that the Interpersonal Defense Theory formulation highlights the complex temporal pattern of recurring coordination failures that characterized Sharon's behavior, specifically, the ways in which she stubbornly pressed on with her point of view, while she also repeatedly appeared to agree with and defer to the other person, whereas the IRT formulation identifies a set of features that were characteristic of Sharon's behavior with others. The IRT formulation indicates that Sharon's behavior was complicated because, for example, it included "complying resentfully" and "defying indirectly," but it does not tell us that those two features were intrinsically related to one another due to the temporal grammar of Sharon's pattern (i.e., that Sharon's complying was resentful and her defying was indirect because the relevant parts of her pattern repeatedly derailed each other).

Another point is that due to its descriptive focus, the IRT formulation does not consider the goals Sharon was pursuing regarding her ongoing relationships by behaving the way she did. By treating that issue as a key concern and examining how interaction is organized over time, the Interpersonal Defense Theory approach helps us see that what IRT views as "defying indirectly" actually included repeated attempts by Sharon to take a stand. Taken by themselves, those attempts were efforts to pursue Sharon's central interpersonal wish that others would affirm and appreciate her for her viewpoints and independence. Recognizing that part of Sharon's pattern played this role with respect to her wish is important. According to Interpersonal Defense Theory, even though Sharon's efforts at taking a stand were part of a Red pattern, they needed to be nurtured.

The formulation based on Interpersonal Defense Theory also calls for considering what the IRT account identifies as "complies resentfully" from a viewpoint that focuses on the role parts of Sharon's behavior played with respect to her interpersonal goals. Sharon's pattern included repeated bids in which she agreed with or deferred to others. Because she repeatedly derailed those apparently compliant bids by shifting to taking a stand/pursuing her viewpoint, it does make sense to say that she complied resentfully. However, according to Interpersonal Defense Theory, the key point to recognize is that as part of her noncoordinating pattern, agreeing/deferring worked against her fear of being ignored/neglected. Sharon's defensive use of agreeing/deferring was not something that should have been nurtured, but it might well have made a difference if her therapist recognized why Sharon kept agreeing/deferring only to undo those apparently compliant bids again and again.

Earlier, I noted that from a descriptive standpoint, the two approaches offer similar formulations of the ways in which others behaved towards Sharon. Nevertheless, that part of the two formulations differed in other respects. Only Interpersonal Defense Theory maintains that the ways others often responded to Sharon were effects (the feed-forward effects) of how she related to them, and, in addition, offers an explanation of how Sharon's noncoordinating, defensive interpersonal behavior pattern pulled for those responses.

A related difference between the two approaches is that the Interpersonal Defense Theory formulation characterizes how others responded to Sharon in terms of the role played by those 
responses with respect to her wish and fear. The IRT formulation, on the other hand, does not help us see that others behaved towards Sharon in ways that had specific relationships to her wish and fear. Therefore, while neither formulation of others' behavior with Sharon includes "affirmed Sharon and showed appreciation for her viewpoints and independence," only the Interpersonal Defense Theory formulation identifies this as an especially noteworthy absence because it meant that others did not respond to Sharon in the manner she wished-for. Similarly, while neither formulation of others' behavior towards Sharon included "ignored and neglected her," only Interpersonal Defense Theory helps us see that this meant that Sharon's interpersonal pattern enabled her to avoid her central feared response.

Recognizing roles vis a vis Sharon's wish and fear also is important when it comes to the ways others did respond to her. Although both formulations of others' behavior included hostile, controlling responses, only the formulation based on Interpersonal Defense Theory points out that those responses were distinct from her central fear, notwithstanding the fact that they certainly were negative. Furthermore, the Interpersonal Defense Theory formulation maintains that Sharon's interpersonal pattern actually pulled for those responses as one way of avoiding her central fear. This observation puts the fact that others behaved in hostile, controlling ways towards Sharon in a very different light from how one might think about them otherwise.

Similar considerations apply when it comes to the positive ways others often behaved towards Sharon. According to the formulation based on Interpersonal Defense Theory, although others often responded to Sharon in positive ways, those positive behaviors were distinct from Sharon's central wish. For example, the IRT formulation of how others related to Sharon includes "not understand[ing] her needs even when combined with love or concern for her" (Critchfield et al., 2021, Table 1, p. 60). Interpersonal Defense Theory helps us recognize that what was off target about those responses was that they did not affirm and show appreciation for Sharon's viewpoints and independence (her central wished-for response), notwithstanding the love and concern they expressed by treating her in a benignly managing manner.

\section{Comparing IRT Steps $2 \& 3$ with Interpersonal Defense Theory}

In the second step of their IRT formulation of Sharon's case, Critchfield et al. (2021) considered Sharon's current relationships in light of the SASB copy processes. In their third step, they linked their findings about copy processes to the GOL hypothesis. The formulation of the case based on Interpersonal Defense Theory is similar in some respects to this part of the IRT formulation, but the two formulations mostly differ due to the fact that the two approaches asked different questions about the clinical material.

The findings for Step 2 in the IRT formulation offer a complicated picture about how Sharon's current relationships compared to her relationships in the past. Those results include different claims about different relationships concerning how Sharon and her significant others behaved in the past and present and how all of that was related to the three copy processes (Critchfield et al., 2021, pp. 51-52). Overall, according to the IRT formulation, the workings of all three copy processes were evident in Sharon's current relationships. 
Consider the analysis Critchfield et al. (2021, p. 51) offered of Sharon's relationship with her father. According to their formulation, Sharon recapitulated her relationship with her father "by continuing to stay close to him, watching out for him and serving as his confidante, and also by perceiving caring others as controlling or overprotective, wishing to take distance." This observation makes it clear that Critchfield et al. believe that Sharon recapitulated her childhood behavior with her father in their current relationship.

The Interpersonal Defense Theory formulation also includes the view that Sharon's current behavior was similar to how she behaved earlier in life in her relationships with some of her significant others (almost certainly including her father), although that earlier period of time was what I have been referring to as phase 2 of development (starting when she developed patterns of interpersonal defense in late childhood or early adolescence), not phase 1.

However, Interpersonal Defense Theory offers a different viewpoint of what the similarity was between Sharon's earlier and adult behavior. According to Interpersonal Defense Theory, that similarity may well have included "staying close" to significant others, for example, but that specific behavior probably was part of a complex noncoordinating defensive pattern that played a functional role with respect to Sharon's central wish and fear. The IRT formulation hints at this idea by noting that in addition to "staying close," Sharon also "perceiv[ed] caring others as controlling or overprotective, wishing to take distance." The clinical material does not include sufficient evidence to draw definite conclusions here, but Interpersonal Defense Theory suggests that it may well have been the case that Sharon not only "wish[ed] to take distance" from her controlling and overprotective father, but that starting in phase 2 she actually behaved towards him in complicated noncoordinating ways in which she "stayed close" (i.e., went along with what her father wanted to do and his point of view) while she also took distance by going off in directions of her own choosing rather than his choosing when she was with him.

The Interpersonal Defense Theory formulation also differs from the IRT formulation of recapitulation in Sharon's relationship with her father with regard to why there were similarities between Sharon's behavior in her earlier relationship with her father and her behavior in her current relationships. From the IRT standpoint, this is where the third step of a formulation comes into play, that is, the GOL hypothesis. According to IRT, by recapitulating how she behaved in her relationship with her father earlier in life in her current relationships with her father and other people as well, Sharon employed copy processes to stay loyal to her father so that she could "finally receive love and understanding from the internalized family in the head" (Critchfield et al., 2021, p. 55).

By contrast, according to Interpersonal Defense Theory, although it is quite common that the defensive interpersonal patterns people engage in as adults often date back to how they related to significant others much earlier in life (in phase 2), the reason for this is not the workings of copy processes or a motivation to remain faithful to internalized attachment figures. Instead, and in keeping with its primary focus on action, Interpersonal Defense Theory offers an explanation based on what people are trying to do in their actual interpersonal relationships and how the way they go about pursuing those goals leads to certain processes that promote persistence, as I discussed above in this paper and in my first paper in this set of articles. 
The IRT formulation also includes observations about how Sharon's current behavior with her father seemed to reflect the workings of introjection and identification. From the IRT standpoint, those observations point out other ways Sharon remained faithful to the "internalized family in the head." Interpersonal Defense Theory does not include any tenets that parallel these two copy processes. It does, however, provide a basis for speculating about other ways to explain introjection and identification that do not rest on the GOL hypothesis.

With regard to introjection (i.e., treating oneself the way significant others treated you), it may well be the case that introjected processes play roles supporting defensive patterns. This would parallel how Interpersonal Defense Theory conceptualizes the roles played by the traditional intrapsychic mechanisms of defense. For example, introjecting her father's overprotective stance toward her would lead Sharon to be overprotective of herself. Treating herself that way would support the parts of Sharon's defensive pattern that served to avoid her fear. Specifically, introjected overprotectiveness would support repeatedly shifting away from taking an independent stand to agree with and defer to others.

Turning to the copy process of identification, without invoking the GOL hypothesis, Interpersonal Defense Theory can make sense of the intriguing observation that a person may relate to some other people in ways that are similar to how a significant other related to him or her. It may well be the case that specific features of an individual's interpersonal defenses are learned from significant others through modeling and then incorporated in the defensive pattern. For example, Critchfield et al. (2021, p. 51) maintained that via identification Sharon copied her father's overprotectiveness towards her in how she related to him and other people. It seems clear that Sharon incorporated overprotectiveness to others in her defensive pattern. One instance of this occurred when Sharon and Jeff were on their way to do something and happened to run into Sharon's father as they were walking. Sharon told Jeff that they had to skip their plans and have lunch with her father because she was very concerned about how her father would feel if they did not do that. In this way, Sharon was able to take a stand towards Jeff, although to be sure this was a defensive stand taken on behalf of her father.

\section{COMPARING IMPLICATIONS FOR TREATMENT}

The fourth and final step in the process for arriving at an IRT case formulation calls for setting out the treatment implications that follow from the first three steps. In two basic respects, the IRT approach to treatment is similar to the approach based on Interpersonal Defense Theory. According to both perspectives, psychotherapy should aim at helping patients change maladaptive interpersonal patterns. The two perspectives also share the view that a wide variety of kinds of interventions can contribute to that goal.

Nevertheless, IRT and Interpersonal Defense Theory lead to very different ideas about how therapists should try to help patients change dysfunctional patterns. In what follows, I first offer general points about differences between the two perspectives regarding how therapists should pursue insight-oriented work and how they should act towards their patients at the level of therapy relationship processes. I then return to Sharon's case and discuss ways in which the two perspectives differ in their recommendations about how Sharon's therapist might have 
employed insight-oriented interventions and enacted interventions at the level of therapy relationship processes in his work on that case.

\section{Comparing Treatment Implications in General}

\section{Differences in General Regarding Insight-Oriented Efforts}

According to IRT, insight-oriented efforts should be directed towards helping patients understand what their current maladaptive interpersonal patterns are like, how those patterns are reenactments of events in their early relationships that reflect the workings of copy processes, that reenacting early relationships is motivated by the GOL hypothesis, and that it is possible for them (patients) to "differentiat[e] from internalized attachment figures" to reclaim what IRT calls the "Birthright Self" by shifting to Green patterns of relating to others (Critchfield et al., 2021, p. 47). As a result of its focus on functional processes that involve the temporal organization of the parts of interpersonal patterns, Interpersonal Defense Theory calls for insight-oriented efforts that differ from this summary of the IRT approach on every count.

From the standpoint of Interpersonal Defense Theory, it is less important to help patients arrive at a descriptive appreciation of what their current interpersonal patterns are like than it is to guide patients towards insights about their central interpersonal wishes, especially, and their fears as well. The reason for this is that Interpersonal Defense Theory maintains that maladaptive interpersonal patterns are attempts to negotiate wish-fear conflicts, and most often patients are not aware of their central interpersonal wishes or fears. Arriving at insights about the wish and fear can contribute to a shift to nondefensive ways of relating to others.

Note that according to Interpersonal Defense Theory, helping a patient understand his or her wish includes realizing that the patient's behavior is a key part of the wished-for kind of relationship; the wish does not only refer to the other person's response. I should also note that effective insight-oriented efforts along these lines typically are not didactic, or psychoeducational, in nature. In addition, insight-oriented interventions aimed at exploring the patient's wish can be useful even when the therapist may not have formed any idea yet about what the wish is. For example, whether the therapist has arrived at a formulation of the case or not, it is often quite helpful to ask a patient, "When you [said or did] that, was there something you were hoping that [Person X] would [say or do]?"

A therapist guided by Interpersonal Defense Theory might also help a patient gain insight about his or her interpersonal pattern. However, the goal of such efforts would not be arriving at a descriptive account of how the patient relates to others and then later showing that the pattern copies an old way of relating to key figures during the patient's childhood, as in IRT. Rather, the goal would be helping the patient recognize that the pattern is a noncoordinating, defensive effort that mixes together in a complex way attempts to pursue a wish with efforts to avoid a fear - an effort that actually works against the patient realizing his or her wish. Here again, when effective, such efforts typically are not didactic in nature, but rather interventions that help patients realize and struggle with their conflicting feelings. 
Whereas IRT emphasizes drawing parallels between current relationship patterns and the patterns that characterized early relationships, recognizing such parallels is not that important according to Interpersonal Defense Theory. In fact, according to the theory, it is more important to recognize how relationship processes in phase 1 of childhood were different from current ones. Exploring these differences is important for two reasons, both of which are based on the view that in phase 1 a child probably repeatedly pursued a particular kind of interpersonal response that he or she really wanted (which later becomes the central interpersonal wished-for response) in a nondefensive manner and encountered a particular negative response (which later becomes the central feared response). The first point here is that inquiring about those early relationship events can help a therapist identify a patient's central wish and fear. The other point is that revisiting those early events can help patients gain insight into their central wishes and fears.

It can be useful to help patients recognize the parallels between relationship processes in phase 2 of development and current relationships, but even insight-oriented work of this sort based on Interpersonal Defense Theory differs from IRT. According to IRT, such parallels reveal continuity in problematic Red patterns that a patient remains loyal to as a Gift of Love. From the vantage point of Interpersonal Defense Theory, noncoordinating defensive patterns are attempts to change things such that the patient realizes his or her interpersonal wish. As dysfunctional as they are, those patterns include something good that should be recognized and nurtured. They are not entirely Red because they include repeated efforts to pursue the wish. Improvement does not result from foregoing old patterns in toto, but from pursuing the wish more fully rather than in a halting or hidden manner. In addition, according to Interpersonal Defense Theory, improvement does not result from insight-oriented efforts aimed at helping patients let go of the "internalized family in the head," but from insight-oriented interventions that help a patient let go of protecting him- or herself from the fear about what might happen if the patient nondefensively pursues his or her wish in actual ongoing relationships.

This last point is closely related to another difference between IRT and Interpersonal Defense Theory. IRT describes Green interpersonal behavior patterns, which it takes as the goal of treatment, in generic terms. They are characterized as "adaptive ways of being" (Critchfield et al., 2021, p. 44) that "involve context-appropriate friendliness with the self and in normative social settings, along with reciprocity of focus and moderate degrees of both enmeshment and differentiation" (Critchfield et al., 2021, p. 45).

By contrast, Interpersonal Defense Theory calls for viewing the goal of therapy idiographically. Therapists should help each patient gain insight into and hopefully resolve his or her own struggle between pursuing a particular interpersonal wish and a particular interpersonal fear that might result from pursuing the wish. This is different from helping a patient become more adaptive in general by "free[ing]" the patient from loyalty to internalized figures from the past (see Critchfield et al., 2021, p. 55). I believe that the Interpersonal Defense Theory approach to insight-oriented work provides individual patients with more positive guidance about how to move in the direction of change than does IRT. 


\section{Differences in General Regarding Therapy Relationship Processes}

Although both IRT and Interpersonal Defense Theory recognize that how therapists relate to their patients is very important, they conceptualize this aspect of the therapeutic process very differently. This difference reflects the fact that Interpersonal Defense Theory focuses primarily on action whereas IRT focuses more on intrapsychic processes.

IRT views the therapy relationship as the crucial foundation that makes possible productive work on therapeutic tasks. Those tasks themselves are primarily viewed in terms of the development of insight. As Critchfield et al. (2021, p. 54) said in a comment about Sharon's case, if the requisite foundation had been established in that case, it would have facilitated "the task of helping her learn about and understand her Red patterns and their origins in close attachment relationships." IRT offers a general recommendation about how therapists should relate to their patients to establish a good foundation. According to IRT, it involves "using a collaborative, compassionate and patient process" (Critchfield et al., 2021, p. 56).

According to Interpersonal Defense Theory, how therapists relate to their patients can contribute to successful outcomes in a more direct way through enacted interventions at the level of therapy relationship processes that help patients change how they relate to their therapists. They can do this by minimizing countertransferential responses (i.e., negative responses distinct from the patient's fear and positive responses distinct from the wish as well) and, instead, relate to their patients in a manner that realizes a patient's central wish and encourages the patient to continue to pursue his or her wish. As I explained in my earlier article in this module, relating to patients in this manner does not simply involve behaving a certain way independently of how the patient acts. A therapist can only respond to a patient in a way that realizes the patient's wish when the patient contributes to the exchange with a bid, or at least part of a bid that is an instance of pursuing the wished-for response. When this pattern involving both the patient's behavior and the therapist's response occurs, it provides the patient with a corrective emotional experience that can help the patient more consistently relate to the therapist nondefensively. This shift from defensive to nondefensive interpersonal behavior in the therapy relationship can then generalize to other significant relationships in the patient's life.

Note that this is an idiographic approach. For example, an intervention by a therapist that enacts benign guidance (e.g., SASB 144, sensible analysis) could well be one patient's wishedfor response, whereas the same intervention might be a positive response distinct from another patient's wished-for response, if that second patient's wished-for response is to be confirmed as $\mathrm{OK}$ as is (SASB 113). Whereas IRT would treat both of these responses (i.e., SASB 113 and 144) as helpful for both patients, Interpersonal Defense Theory would view enacting benign guidance as helpful for the first patient and problematic for the second, especially if the therapist enacted benign guidance frequently in the second case. 
Pragmatic Case Studies in Psychotherapy, http://pcsp.libraries.rutgers.edu

Volume 17, Module 1, Article 5, pp. 63-84, 04-19-21 [copyright by author]

\section{Comparing Treatment Implications for Sharon's Case}

\section{Differences Regarding Insight-Oriented Efforts in Sharon's Case}

As Critchfield et al. (2021, p. 56) explained, if Sharon's therapist had been guided by IRT, he would have directed considerable effort to helping Sharon understand what her maladaptive interpersonal pattern was like and how it "reflect[ed] loyalty to her father and his ways of being." The therapist's goal would have been to "help [Sharon] come to terms with maladaptive ways and values internalized in close attachment relationships" (p. 58).

Interpersonal Defense Theory, on the other hand, does not lead to the view that Sharon's therapist should have helped her identify how her current interpersonal behavior "copied" relationship processes from early relationships with significant others. In addition, it would not call for placing so much emphasis on helping Sharon arrive at an appreciation of a descriptive characterization of what her current pattern was like. Instead, it suggests that the main goal of the therapist's insight-oriented efforts should have been helping Sharon understand her central interpersonal wish. For example, if the therapist had been guided by this basic idea, when Sharon talked about a relationship event, he might have asked her how she hoped the other person would have responded to her. He also might have inquired about how Sharon wishes she had behaved in that interaction because Sharon's wished-for kind of relationship included her behavior as well as the other person's response.

In addition, the therapist might have engaged Sharon in an exploration of some of her early memories because during phase 1 of development children often pursue their wished-for interpersonal responses in a straightforward manner. Those early memories might have provided a good way for Sharon and the therapist to arrive at insights about both the Sharon's wished-for response and how she would behave in her wished-for kind of relationship.

From the vantage point of Interpersonal Defense Theory, Sharon's therapist certainly could have directed some efforts to helping Sharon understand what her defensive pattern was like but, in contrast to IRT, those efforts would have focused on the functional role played by the parts of her pattern given how they were organized temporally. For example, the therapist might have helped Sharon arrive at an understanding that she repeatedly attempted to pursue her wish by again and again going back to present her point of view. Efforts along these lines can contribute to positive outcomes because they help patients recognize that they are already engaged in pursuing a wish even if not in an effective manner.

In addition, Sharon's therapist also might have helped Sharon understand that (a) other parts of her pattern (i.e., the ways she repeatedly shifting away from pursuing her wish to agree with and defer to others) served a different function, avoiding her fear of being ignored and neglected, (b) repeatedly derailing her attempts to pursue her wish made it very unlikely that her wished-for responses would occur, and (c) the overall noncoordinating pattern actually promoted attacking responses and controlling responses that were at times hostile in nature and at other times attempts at benign management. 
Another point about differences in insight-oriented efforts concerns whether and, if so, in what ways each of the two approaches would lead Sharon's therapist to help point her in the direction of change. According to IRT (Critchfield et al., 2021), "progress coming to terms with internalized attachment figures is a key mechanism of change" (p. 58) that can be accompanied by "envisioning and practicing healthier relational alternatives and conflict resolution strategies" (p. 56). However, regarding what those "healthier... alternatives" might be like in Sharon's case, Critchfield et al. (p. 56) had little to say other than a reference to "considering alternatives that involve more self-assertion and direct communication." 5

As I understand it, this lack of specificity regarding the direction of change for Sharon follows from the fact that IRT sees change as the result of letting go of loyalty to the "family in the head." This letting go process leaves the patient open to relating to others in adaptive ways, understood in general terms, but it does not point in a positive way to the nature of those new patterns. It only frees the patient from faithfulness to the old patterns.

By contrast, the suggestions I offered above about insight-oriented efforts that Sharon's therapist might have made about her interpersonal pattern would have offered a good deal when it comes to pointing to the direction of change. In particular, helping Sharon gain insight about her central interpersonal wish would have opened up fruitful lines of inquiry about what Sharon might have done given her wish that others would affirm her and show appreciation for her independence and viewpoints. Exploring that issue might have contributed in a positive sense to helping Sharon change how she related to others.

It might have led her to relate to others in a nondefensive manner in which she embraced her wish and pursued it fully - even though in Sharon's wished-for kind of relationship she would have behaved as per SASB codes 218 (own identity and standards, 217 (assert on own), and 216 (put cards on table), which are not "moderate" in degree of differentiation and, therefore, lie outside the IRT generic characterization of Green patterns, which I discussed earlier. Alternatively, that exploration might have led Sharon to forego her wish at least in certain respects in some relationships for the sake of avoiding her fear and change to relating to certain people by nondefensively "following" them. In either case, the insight-oriented work would have accomplished much more than freeing Sharon from her problematic interpersonal pattern and opening her up to becoming more adaptive in a general sense, because both outcomes would be ways of resolving the particular wish-fear conflict that Sharon was struggling with.

\section{Differences Regarding Therapy Relationship Processes in Sharon's Case}

Critchfield et al. (2021, p. 57) maintained that it was unfortunate that Sharon's therapist "often appeared to control the process of therapy by presenting his take on her situation in a relatively confrontational manner and offer[ing] interpretations that were quite critical in content." They argued that a different approach was needed that "attended to their alliance and collaboration toward shared goals" (p. 58) and that "careful rapport building and intentional collaborative planning [was] essential" (p. 56). They also explained that this approach to the therapy relationship was necessary because it would help Sharon engage in the insight-oriented tasks that would enable her to "come to terms with maladaptive ways and values internalized in 
close attachment relationships" (p. 58). That is, they viewed a good therapy relationship as what I referred to earlier as the requisite "foundation" for what they took to be the "actual work."

In my earlier article in this set of papers, I made it clear that Interpersonal Defense Theory leads to a different view about how Sharon's therapist should have related to Sharon at the process level and why he should have behaved towards her in those ways. According to Interpersonal Defense Theory, what a therapist says and does are interpersonal acts and, as such, a therapist's contributions to therapeutic exchange can directly influence how the patient relates to the therapist. Depending on what they are like when viewed as interpersonal acts and how that relates to the formulation of each particular case, a therapist's contributions can promote a shift on the patient's part from relating to the therapist in a defensive manner to behaving nondefensively with the therapist. However, a therapist's contributions can serve, instead, to maintain a patient's defensive pattern of engaging in his or her relationship with the therapist.

As I explained in my earlier paper, Sharon's therapist related to her in ways that perpetuated her defensive pattern because many of his bids were countertransferential, as that concept is understood in the Interpersonal Defense Theory. Note that this point includes his attempts at benign management (e.g., SASB 144, sensible analysis), which were positive responses distinct from Sharon's central wished-for response, whereas IRT would view those therapist bids as helpful because they appear to be bids that facilitate insight-oriented efforts.

According to Interpersonal Defense Theory, Sharon's therapist should have behaved towards her much more frequently in ways that were examples of her central wished-for response by affirming her and showing appreciation for her independence and points of view (in SASB terms, encourage separate identity, 118; you can do it fine, 117; and carefully fairly consider, 116), and that encouraged Sharon to continue pursuing her wish by taking stands and acting independently (in SASB terms, own identity and standards, 218; assert on own, 217; and put cards on table, 216). Such enacted interventions by the therapist might well have helped Sharon shift to relating to him in a nondefensive manner. ${ }^{6}$ As I noted in the previous subsection, this approach departs from IRT because the therapist would be trying to promote interpersonal behavior on Sharon's part that is not moderate in degree of differentiation and, therefore, lies outside the IRT generic characterization of Green patterns.

Interpersonal Defense Theory's appreciation of the role that can be played by enacted interventions at the level of therapy relationship processes also includes another consideration that is not part of IRT. According to the theory, patients' interpersonal wishes refer to interaction sequences in which another person makes the wished-for response when the patient pursues his or her wish. Because Sharon often covered over her attempts to pursue her wish with the other part of her defensive pattern, the theory alerts us that in order to make possible corrective emotional experiences (in which Sharon pursued her wish and the therapist responded in the wished-for manner instead of with the feared response), Sharon's therapist would have had to carefully attend to and pick up on the parts of her contributions that were efforts to pursue her wish and then respond in her wished-for manner to those parts. In my prior paper in this module, I gave an example of how Sharon's therapist might have done this at one point in the transcript considered there. 


\section{CONCLUDING COMMENTS}

In this paper, I compared IRT with an approach to psychotherapy based on Interpersonal Defense Theory, both in general terms and with respect to their views of Sharon's case. Although both are interpersonal approaches that incorporate ideas from SASB, they differ in a number of significant ways. I have tried to point out those differences as clearly as possible, albeit to be sure, from the vantage point of Interpersonal Defense Theory.

One question for future consideration is whether there is some way to integrate these two approaches to understanding patients' problems and what constitutes effective therapeutic work. Theoretical integration (finding a superordinate model that can encompass the two perspectives) poses a daunting challenge because the differences between IRT and Interpersonal Defense Theory are rooted in divergent fundamental commitments. Nevertheless, it may be possible.

In my clinical work, I have taken a very small step along the lines of assimilative integration (see Messer, 2001), by employing one element from IRT in my work with some patients in a way that is guided by the framework of Interpersonal Defense Theory. I have found that some patients find it helpful to use the labels "Red" and "Green" from IRT as a shorthand for remembering and referring to what they experienced as prototypical concrete examples of relationship events in their lives that went poorly and well, respectively. The Interpersonal Defense Theory framework comes into play because these concrete examples usually very clearly involve some key parts of the formulation of the given case based on the theory. Patients typically find it helpful when I point to some feature of a Red or Green example and make an observation that links that feature to part of the Interpersonal Defense Theory-based formulation. For example, I might point to the way the patient behaved in a Green example and ask whether that is how the patient wishes he or she related to others more often. I imagine that there are many other ways of drawing on one of these two approaches to augment the other. 


\section{REFERENCES}

Benjamin, L. S. (1979). Structural analysis of differentiation failure. Psychiatry: Journal for the Study of Interpersonal Processes, 42, 1-23.

Benjamin, L. S., \& Critchfield, K. L. (2010). An interpersonal perspective on therapy alliances and techniques. In J. C. Muran \& J. P. Barber (Eds.), The therapeutic alliance: An evidence-based guide to practice (pp. 123-149). New York: The Guilford Press.

Critchfield, K.L., Dobner-Pereira, J., \& Stucker, E. (2021a). The case of Sharon considered from the vantage point of Interpersonal Reconstructive Therapy.

Pragmatic Case Studies in Psychotherapy, 17 (1), Article 4, 42-62. Available: http://pcsp.libraries.rutgers.edu/

Messer, S. B. (2001). Introduction to the special issue on assimilative integration. Journal of Psychotherapy Integration, 11, 1-4

Wachtel, P. L. (1994). Cyclical processes in personality and psychopathology. Journal of Abnormal Psychology, 103, 51-54.

Wachtel, P. L. (2008). Relational theory and the practice of psychotherapy. New York, NY: Guilford.

Wachtel, P. L. (2017). The relationality of everyday life: The unfinished journey of relational psychoanalysis. Psychoanalytic Dialogues, 27, 503-521.

Westerman, M. A. (2005). What is interpersonal behavior? A post-Cartesian approach to problematic interpersonal patterns and psychotherapy process. Review of General Psychology, 9, 16-34.

Westerman, M. A. (2013). Making sense of relational processes and other psychological phenomena: The participatory perspective as a post-Cartesian alternative to Gergen's relational approach. Review of General Psychology, 17, 358-373.

Westerman, M. A. (2017). Building on Wachtel's points about implications of Mitchell's ideas: Suggestions based on the participatory philosophical perspective for locating the person in The world of practical activities. Psychoanalytic Dialogues, 27, 530-545.

Westerman, M. A. (2018). Interpersonal defense theory: An integration of philosophical considerations, psychoanalytic concepts, and perspectives on interpersonal processes that provides a guide for a wide range of therapeutic interventions. Journal of Psychotherapy Integration, 28, 310-328.

Westerman, M. A. (2019). Case formulation in interpersonal defense theory: A process model of interpersonal phenomena that play key roles in psychopathology and psychotherapy. In U. Kramer (Ed.), Case formulation for personality disorders: Tailoring psychotherapy to the individual client (pp. 315-335). London, United Kingdom: Elsevier.

Westerman, M.A. (2021a). The case of Sharon considered from the vantage point of Interpersonal Defense Theory. Pragmatic Case Studies in Psychotherapy, 17 (1), Article 3, 19-41. Available: http://pcsp.libraries.rutgers.edu/

Westerman, M. A., \& Muran, J. C. (2017). Investigating an approach to the alliance based on interpersonal defense theory. Psychotherapy Research, 27, 620-641.

Westerman, M. A., \& Steen, E. M. (2007). Going beyond the internal-external dichotomy in clinical psychology: The theory of interpersonal defense as an example of the participatory approach. Theory \& Psychology, 17, 323-351. 


\section{ENDNOTES}

${ }^{1}$ Interpersonal Defense Theory offers process models that are different in certain respects from most such models in psychology. Typically, process models examine temporal relationships between behaviors, but they treat each of the steps in the overall process as an independent phenomenon that is linked over time with other steps by billiard ball-type causal relationships. According to Interpersonal Defense Theory, causal relationships between interpersonal behaviors link together the parts of larger patterns of interaction (see Westerman, 2013, pp. 368-371).

${ }^{2}$ Interpersonal Defense Theory draws on Wachtel's $(1994,2008)$ cyclical psychodynamics in a number of ways including this idea that persistence is not based on supposedly stable inner representations, but rather results from the fact that how a person tries to change things actually keeps them the same. However, in a number of respects, Interpersonal Defense Theory conceptualizes the processes involved in persistence quite differently from how they are viewed in cyclical dynamics (see Westerman, 2017, pp. 539-541).

${ }^{3}$ I believe that the interpersonal processes described in the second pattern are "surface" phenomena that can be explained by my account of Sharon's defensive pattern. According to Critchfield et al.'s (p. 60) description of what they consider her second pattern, Sharon "perceives self as focused on meeting the needs of others, monitors and worries about them." In many of Sharon's narratives that included expressions of concern about others, those concerns appeared to have played a part in her defensive pattern. For example, in one session, Sharon said that Jeff often got annoyed when she decided to end an evening at an early time. Her explanation on those occasions was that she felt she needed to return to the apartment she shared with her sister so that her sister would not be home alone. Sharon may well have felt concern for her sister, but deciding to go home early also was an example of how she often invoked her concerns about third parties as an unclear manner of insistently doing something like taking an independent stand vis a vis the person she was with at the time.

${ }^{4}$ Critchfield et al. (2021, p. 60) used the word "ignore" in the part of their Table 1 about how others acted toward with Sharon. However, that word appears as part of SASB complex codes in which the usual meaning of "ignore" does not apply. For example, the code "Control + Ignore" refers to control that is implemented out of any reasonable context, makes no sense, or is impossible to comply with (personal communication, K. Critchfield, Sept 10, 2018).

${ }^{5}$ It is not clear to me how the IRT formulation of Sharon's case leads to Critchfield et al.'s (2021) positive suggestion about "more self-assertion." I believe this suggestion actually reflects a reasonable extra-theoretical (vis a vis IRT theory) observation because being self-assertive was not the only way that Sharon might have begun to behave adaptively. In addition, note that in a sense Sharon was very self-assertive. She persistently shifted back to her own point of view. Even if we accept the idea that Sharon needed to become more assertive, the real issue concerns what changes that would entail. In Sharon's case, the key change would involve no longer repeatedly derailing the bids or parts of bids in which she took a stand, not whether she frequently took stands. In other words, the key change would have involved the temporal organization of Sharon's pattern, which Critchfield et al.'s formulation did not consider. A final point: As I indicate shortly below in the text, Sharon might have resolved her conflict by becoming less assertive. Interpersonal Defense Theory provides positive guidance for what IRT would call a patient's Green pattern, not because it identifies particular behaviors a person should start to engage in, but because it recognizes that for each patient, the direction of change involves arriving at some resolution of his or her wish-fear conflict.

${ }^{6}$ Also, a therapist bid that encouraged Sharon's separate identity (SASB 118) might well have facilitated collaborative insight-oriented work more successfully than a bid that offered sensible analysis (SASB 114). 
Figure 1. Structural Analysis of Social Behavior (SASB). Full Model except figure omits the introject surface and includes only the two interpersonal surfaces. Figure 2 on p. 6, Benjamin, L.S. (1979). Structural analysis of differentiation failure. Psychiatry: Journal for the Study of Interpersonal Processes, 42, 1-23. Reprinted with permission of Guilford Press.

\section{INTERPERSONAL}

\section{OTHER}

\section{SELF}

\section{Endorse freedom}

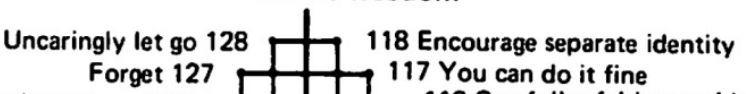

Ignore. pretend not there 126

Neglect interests, needs 125 Illogical initiation 124 Abandon, leave in lurch 123

Starve, cut out 122 Angry dismiss, reject 121 Annihilating attack 130 Approach menacingly 131

Rip off, drain 132 Punish, take revenge 133 Delude, divert, mislead 134 Accuse, blame 135

Put down, act superior 136 Intrude, block, restrict 137

Enforce conformity 138

Forget 127
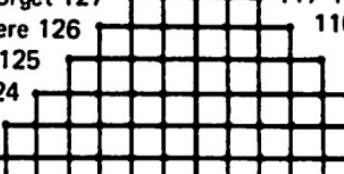

\section{Manage, control 140}

\section{Freely come and go}

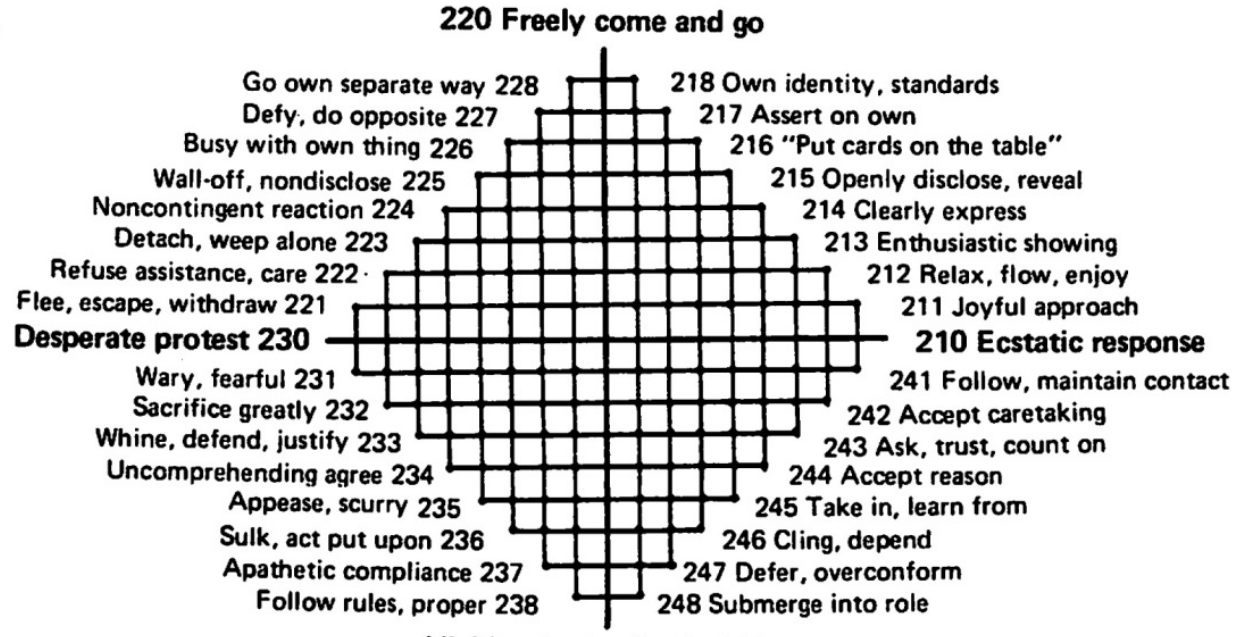

Yield, submit, give in $\mathbf{2 4 0}$ 